\title{
Nos trilhos da cultura ferroviária: documentos de arquivo familiar no ensino de história
}

Daniel Augusto Arpelau Orta*

\section{RESUMO}

Este artigo aborda a historicidade do ensino de História, apontando como a metodologia da História foi utilizada e quais foram suas finalidades. Após este ponto, esta pesquisa definiu algumas das características do ensino de História, e uma das finalidades atuais, empregando conjuntamente a tematização de conteúdos e o uso de documentos em estado de arquivo familiar. Posteriormente, este artigo faz uma descrição de um exemplo possivel de documentação, presente no arquivo familiar do autor do artigo, e que diz respeito à profissão ligada à ferrovia e suas práticas culturais e sociais. Desenvolvem-se problemáticas, ao mesmo tempo em que é incluído um suporte historiográfico para conectar os documentos familiares com os conceitos temáticos de cultura, memória e trabalho.

Palavras-chave: Ensino de História, Construção do conhecimento histórico, Documentação familiar.

\section{Contexto da disciplina de História}

Observando autores como François Furet, Elza Nadai, Maria Auxiliadora Schmidt, Philippe Artières, para não citar outros, ou mesmo os documentos dos Parâmetros Curriculares Nacionais (PCN) e as Orientações Curriculares da Secretaria de Educação do Estado do Paraná, pode-se perceber claramente a trajetória que a ciência histórica percorreu principalmente nos séculos XIX e XX. Furet, por exemplo, aponta questões que circuncidavam os pensadores iluministas antes e após a Revolução Francesa: "[...] aquilo que os homens do século XVIII tinham batizado de 'história filosófica': uma reflexão sobre a

\footnotetext{
* Graduado em História / UFPR.
} 
evoluçãa dos povos e das civilizações, um estudo do passado indispensável para a análise do progresso da humanidade nas vias da razão". (FURET, s.d., p.120). Razão que depois foi transformada em cientificismo, revestida do prestígio intelectual de instituições como as universidades e academias, ou mesmos os institutos nacionais de História e Ciência. Possuía um método e um objeto, servia à legitimação de Estados e Nações; e tinha, portanto, a finalidade de formar "um cidadão': "fatos, datas e nomes foram construídos pela história oficial ao longo do século XIX que tinham como finalidade legitimar o Estado Nacional em formação, pois este não fora construído através de ampla participação social." (PARANÁ, 2005, p.2).

Com o regime republicano no Brasil, "a incorporação da concepção de que a disciplina histórica tinha a responsabilidade de formar os cidadãos ganha força, como demonstram as diretrizes da Lei de Educação de 1931 e 1961, bem como os programas que passaram a ser utilizados nas escolas." (SCHMIDT \& CAINELLI, 2004, p.10-11). Nos anos de 1950-1960 houve, segundo os autores acima citados, uma tímida preocupação em mais do que descrever fatos buscar explicações generalistas, tendo a disciplina o papel de formar pessoas críticas: "no pós-guerra e no contexto da democratização do país (1945-1960), com o fim da ditadura Vargas, a disciplina de História passou a ser novamente objeto de debates quanto as suas finalidades e relevância na formação política dos alunos". (PARANÁ, 2005, p.2).

E nos últimos quarenta anos, verificou-se no campo dos estudos históricos uma nova guinada nas questões referentes ao objetivo das pesquisas e do ensino, em oposição seja pelo conservadorismo e rigidez que os governantes militares impuseram (educação moral e cívica), seja pelas novas concepções epistemológicas do campo historiográfico: "as reflexões apresentadas neste período apontam a existência de diversas abordagens e temáticas para o ensino de História, além de questionamentos acerca dos conteúdos curriculares, das metodologias de ensino, do livro didático e das finalidades de seu ensino". (SCHMIDT \& CAINELLI, 2004, p.11).

No ano de 1997 foram editados os Parâmetros Curriculares Nacionais, que trouxeram sugestões em todas as disciplinas sobre as possibilidades teóricometodológicas de ensino. Sobre o ensino de História, as Orientações Curriculares do Estado do Paraná criticam algumas considerações dos Parâmetros 
Curriculares Nacionais (capacidades, competências, interdisciplinaridade, entre outras), e defendem a importância de que

[...] o conhecimento histórico é selecionado e construído na relação entre as experiências sociais dos sujeitos (acontecimentos, comportamentos, apropriações) e as estruturas sócio-históricas, a partir da utilização rigorosa de conceitos historiográficos no processo de investigação que permitam compreender os espaços de atuação social destes agentes históricos. Entenda-se que este rigor deve estimular a criação de novas significações ou sentidos no universo da disciplina de História através da produção de narrativas históricas. (PARANÁ, 2005, p.4).

E é neste sentido de estimular novas significações que a proposta de trabalhar com documentos em estado de arquivo familiar pode ser visualizada, pois é entre as categorias teóricas propostas e os conteúdos dos documentos que. uma narrativa histórica pode ser elaborada; e estas narrativas históricas nada mais são do que o produto da cognição destas interpretações expressadas no sentido que os autores destas lhes conferem. Maria Auxiliadora SCHMIDT e Marlene CAINELLI reiteram estas idéias e escrevem sobre este uso do documento como proposta pedagógica:

A concepção renovadora de documento e de seu uso em sala de aula parte do pressuposto de que o trabalho com documentos históricos pode ser ponto de partida para a prática de ensino de História. Nessa perspectiva, os documentos não serão tratados como fim em si mesmos, mas deverão responder às indagações e às problematizações de alunos e professores, com o objetivo de estabelecer um diálogo com o passado e o presente, tendo como referência o conteúdo histórico a ser ensinado. (SCHMIDT \& CAINELLI, 2004, p.95).

E a epistemologia contemporânea do documento histórico não considera como fonte histórica tão somente as informações que os Estados produzem, que estão nos livros didáticos, mas qualquer objeto que possua vestígios da trajetória humana, seja fotografias, diários, áudios e vídeos, ou qualquer outra informação de qualquer pessoa.

Nesta linha que Philippe Artières trabalha sobre a pesquisa dos 
documentos arquivados, e como apenas alguns vestígios da trajetória humana são guardados, existe uma seleção destes traços, um arrumar, e "refletir sobre esse 'arrumar-se' é em suma falar de uma coisa comum, [...] dar-lhes sentido e talvez entender um pouco melhor quem somos nós." (ARTIÈRES, 1998, p.11). Este entender é um dos fundamentos possíveis de se pensar a disciplina histórica, e a narrativa produzida através da análise daqueles documentos pode ser a metodologia dos encaminhamentos das questões propostas. Em outras palavras, o diálogo entre o passado e o presente pode ser estabelecido com os documentos guardados em casa e a mediação de conceitos teóricos, na aproximação do cotidiano dos alunos através de temas.

Toda esta descrição acima sobre o fazer da disciplina histórica pôde ilustrar a historicidade que a disciplina percorreu neste período; é reconhecer a construção do conhecimento, independentemente se aquelas pessoas tinham noção disto. Mostra, pois, a finalidade imbricada naqueles modelos e sua articulação no campo de ensino; e permitem refletir sobre as propostas contemporâneas.

\section{Finalidades atuais do ensino de História}

Depois de observarmos quais foram as motivações e justificativas do ensino de História nos últimos dois séculos, a questão sobre a finalidade do ensino atual surge como ponto capital para a abordagem metodológica proposta pelo uso de documentos em estado de arquivo familiar; como utilizar instrumentos que interajam com estas propostas. É nesta linha que Maria Auxiliadora SCHMIDT e Marlene CAINELLI afirmam:

Uma nova concepção de documento histórico implica, necessariamente, repensar seu uso em sala de aula, já que sua utilização hojeé indispensável como fundamento do método de ensino, principalmente porque permite o diálogo do aluno com realidades passadas e desenvolve 0 sentido da análise histórica. 0 contato com as fontes históricas facilita a familiarização do aluno com formas de representaçã̃o das realidades do passado e do presente. (2004, p.94).

Ressaltaria aqui a importância do documento no ensino como forma de incitar uma empatia dos alunos com sua realidade, vendo assim que o 
documento histórico é um meio da construção do conhecimento, e não como uma informação em si, um fato acabado; o documento para ser utilizado é preciso ser interrogado, questionado e interpretado, enfim, tematizado e problematizado.

O termo consciência histórica é muito trabalhado por RÜSEN, considerando que

a disciplina de História na escola é socialmente planejada para intervir positivamente na formação da consciência histórica, a qual está intimamente relacionada à questão dos valores e dos modelos de ação. A consciência histórica é pré-requisito que faz a mediação entre a moral, a nossa ação, nossa personalidade e nossas orientações valorativas. (Apud CERRI, 2004a, p.2).

Enfim, podemos compreender que "a consciência histórica amalgama 'ser' e 'dever' em uma narrativa significante que refere acontecimentos passados com o objetivo de fazer inteligível ao presente, e conferir uma perspectiva futura a essa atividade atual". (idem, p.2).

A produção da narrativa histórica com documentos trazidos pelos alunos pode ser entendida no que Jean Vogler descreveu por memória social neste trecho:

além da memória nacional, outras memórias coletivas podem ser desenvolvidas. A memória familiar é a primeira memória coletiva em que o indivíduo se insere. Cada família tem uma memória marcada pela narrativa da vida de seus membros, pelos acontecimentos, pelas tradições, pelos sistemas de valores. É esse conjunto que constitui sua memória, transmitida de geração a geração, principalmente pela oralidade, mas também pelos documentos escritos, pelas imagens, como fotografias, e pelos lugares. Essa memória coletiva está, evidentemente, relacionada com a das outras famílias, a dos outros grupos, a das outras instituições e com a da sociedade global. Mas ela tem sua particularidade, que constitui sua identidade própria. (Apud SCHMIDT \& CAINELLI, 2004, p.19).

Não significa, pois, ficar preso na história da família, mas conectar esta experiência familiar, esta memória social com o contexto mais amplo também; desta forma, procura-se uma empatia do aluno com o assunto ao mesmo 
tempo em que procura exercitar e desenvolver um espírito crítico. O ensino de História atualmente seria, pois,

a renovação dos conteúdos, a construção de problematizações históricas, a apreensão de várias histórias lidas a partir de distintos sujeitos históricos, das histórias silenciadas, histórias que não tiveram acesso à História. Assim, busca-se recuperar a vivência pessoal e coletiva de alunos e professores e vê-los como participantes da realidade histórica, a qual deve ser analisada e retrabalhada, com o objetivo de convertê-la em conhecimento histórico, em auto-conhecimento. (SCHMIDT \& BRAGA, 2005, p.5).

Acredito ser possível a concatenação da idéia da memória social com a consciência histórica, um espírito crítico, como forma de trabalho da produção da narrativa, pois articula elementos muito próximos da realidade dos alunos e da proposta de levantar questões e interpretações com base nos conceitos sociais.

\section{0 uso de temas no ensino de História}

Atentando a estas preocupações de aproximar dos alunos a construção do conhecimento e sua realidade mais próxima, de romper com um ensino ligado a mera transmissão de informações sem vínculos investigativos, os documentos legais orientam aos professores a utilização de temas, onde a problemática (sincronia) prevalece sobre a descrição (diacronia), mas não a primeira anulando a última. 0 ensino de História atrelado à tematização permite, pois, esta construção de significações, na medida em que com o tema um objeto é delineado, circunscrito e explorado através das categorias de análise social, não importando tanto a linearidade cronológica, mas a orientação coerente das informações extraídas e interpretadas, articuladas na narrativa histórica produzida com base nos documentos selecionados. Em outras palavras, Luís Cerri concebe que a História temática

representa, entre outras perspectivas e demandas, a busca da quebra da linearidade ilusória dos modelos tradicionais e estruturação do conteúdo em torno dos conceitos, visando tanto adaptar assuntos aos interesses / necessidades dos alunos quanto desenvolver uma concepção de História (CERRI, 2004b, p.4). 
Se a História é tudo, ou melhor, tudo pode ser objeto da ciência histórica, então fica explícito que o que é passado nos conteúdos curriculares é apenas uma ínfima parte diante da infinidade de experiências e relações já existentes, e das que ainda virão. Chega-se, pois, a conclusão da filtragem e seleção de conteúdos, objetos e propostas de pesquisa e trabalho dentro da disciplina; muitas vezes estes conteúdos são tidos como 'a' História. Pelo contrário, esta proposta de trabalho com documentos em estado de arquivo familiar e a construção da narrativa produzida pelos alunos com seus documentos seria 'uma' História, uma interpretação e seleção que seguiu uma determinada problemática e uma temática.

Em suma, as Orientações Curriculares do Estado do Paraná defendem como resultado da tematização dos currículos:

a necessidade da valorização dos sujeitos históricos não somente como objetos de análise historiográfica; mas como agentes que buscam a construção do conhecimento através da reflexão teórica e, portanto, da produção conceitual, de sua prática vivencial e investigativa no universo escolar. (PARANÁ, 2005, p.5).

Em outras palavras, trata-se de oferecer um contraponto que permita resignificar as experiências dos alunos no contexto e na duração histórica da qual fazem parte, e também apresentar os instrumentos cognitivos que os auxiliem a transformar os acontecimentos contemporâneos e aqueles do passado em problemas históricos a serem estudados e investigados.

\section{Uma proposta do uso de documentos em sala de aula}

De tudo que foi descrito e comentado acima, passo agora a descrever e sugerir a utilização de documentos em estado de arquivo familiar. Um exemplo possível foi encontrado nos meus pertences familiares, onde selecionei diversos materiais relacionados com o trabalho de meu pai, que foi maquinista ferroviário. São fotos, carteiras de trabalho, manuais técnicos, fitas K-7 e VHS, camisas de futebol e disco de vinil. Pensando sobre a problematização e a tematização, acredito ser interessante a junção dos conceitos de trabalho e cultura, sintetizando-os em uma 'cultura ferroviária', ou seja, os elementos profissionais imbricados nas dinâmicas culturais. 
Estaria, portanto, tematizando o trabalhadore suacultura, mais especificamente a sua rede de amizades, a sociabilidade nos espaços da profissão. Com isso, estou buscando com a pesquisa explorar a riqueza de informações e conexões nestes documentos em estado de arquivo familiar, a importância em verificar as apreensões do passado relacionadas ao trabalho que ultrapassem a noção de 'fábrica' (produção, horário de expediente, greve, escala, luta de classe, etc), a saber: a sociabilidade dos trabalhadores, que não apenas se identificam numa mesma profissão, como também em laços de solidariedade, as atividades extra trabalhistas, que por algum motivo agrupam trabalhadores, o mundo fora das fábricas, ultrapassar os muros das indústrias e sua atividades econômicas. Olhar o trabalho não apenas pelo viés do econômico, mas também do social e cultural.

Enfim, estudar o trabalho através das redes estabelecidas no contato, na experiência e na vivência de pessoas que interpenetraram suas trajetórias, que tiveram algo comum além de uma mesma profissão. Edward THOMPSON, quando procurou abordar esta questão, escreveu: "como homens e mulheres vivem suas relações de produção e segundo a experiência de suas situações determinadas, no interior do conjunto de relações sociais, com a cultura e as expectativas a eles transmitidas e com base no modo pelo qual se valeram dessas experiências em nível cultural." (2001, p.277). Em outras palavras, esta idéia de cultura e experiência pode ser entendida como "os artefatos, as idéias, os signos e símbolos, as linguagens e tudo que permite e realiza as mediações dos e entre sujeitos, em relações sociais historicamente determinadas onde estes sujeitos são produto e também produtores de cultura."(SCHMIDT \& BRAGA, 2005, p.2).

\section{Tipologia dos documentos}

Como são dezenas de fotografia, várias páginas de carteira de trabalho, discos, uniformes de futebol, trechos longos de fitas K7 e VHS, vou selecionar alguns excertos para serem explorados neste texto. Iniciaria com a profissão que o sujeito histórico selecionado exerceu. Usaria, portanto, as carteiras de trabalho que registram as diversas profissões, cargos e atuações ligadas ao trabalho. Além das informações cadastrais, as páginas de contratos de trabalho são riquíssimas de informações, como os pagamentos anuais aos sindicatos e as informações gerais, as regras se segurança no trabalho, etc. Com relação à profissão ligada à ferrovia, nota-se o 
ingresso na Rede Ferroviária Federal no dia 09 de janeiro de 1981. Sistematizando apenas algumas das informações das duas carteiras existentes, como cargos, alterações de salários, chega-se a esta tabela:

Tabela 1 - Seleção de alguns dados referentes à função e valor do salário na área da ferrovia na carteira de trabalho de Roberto Ramon Orta Viacava.

\begin{tabular}{|c|c|c|c|}
\hline Data & Função & Salário & Motivo \\
\hline $09-01-1981$ & Auxiliar de maquinista especial n. ${ }^{\circ} 59$ & $\operatorname{Cr} \$ 12.079,00$ & [Início na RFFSA] \\
\hline 01-05-1981 & Mesma & $\operatorname{Cr} \$ 18.943,00$ & Reajuste salarial \\
\hline 01-05-1982 & Mesma & $\operatorname{Cr} \$ 40.516,00$ & Reajuste salarial \\
\hline $01-11-1982$ & Mesma & $\operatorname{Cr} \$ 59.146,00$ & Reajuste salarial \\
\hline $13-11-1982$ & Maquinista especial n. ${ }^{\circ} 66$ & $\operatorname{Cr} \$ 100.273,00$ & Equiparação salarial \\
\hline $01-05-1983$ & Mesma & $\operatorname{cr} \$ 147.903,00$ & Reajuste salarial \\
\hline 01-05-1984 & Mesma & $\operatorname{Cr} \$ 413.099,00$ & Reajuste salarial \\
\hline 01-01-1985 & Maquinista especial n. 67 & $\operatorname{cr} \$ 768.302,00$ & Equiparação salarial \\
\hline $01-05-1985$ & Mesma & $\operatorname{Cr} \$ 1.607 .436,00$ & Reajuste salarial \\
\hline $01-11-1985$ & Mesma & $\operatorname{Cr} \$ 2.930 .355,00$ & Reajuste salarial \\
\hline $01-05-1986$ & Maquinista especial n. ${ }^{0} 67$ & Cz\$3.960,78 & Equiparação salarial \\
\hline 01-01-1987 & Maquinista especial n. ${ }^{0} 73$ & $\operatorname{Cz} \$ 6.738,46$ & Equiparação salarial \\
\hline 01-03-1987 & Mesma & $\mathrm{Cz} \$ 8.086,15$ & Reajuste salarial \\
\hline $01-05-1987$ & Mesma & $\mathrm{Cz} \$ 13.178,16$ & Reajuste salarial \\
\hline 01-05-1988 & Mesma & $\mathrm{CZ} \$ 74.172,03$ & Reajuste salarial \\
\hline 01-01-1989 & Maquinista especial $n .^{\circ} 74$ & $\mathrm{Cz} \$ 365,26$ & Melhoria salarial \\
\hline 01-05-1989 & Maquinista especial n. ${ }^{0} 75$ & Cz\$ $\$ 992,38$ & Acordo coletivo \\
\hline 01-01-1990 & Mesma & $\mathrm{CZ} \$ 12.505,79$ & Reposição reajuste \\
\hline $01-08-1990$ & P0 1262. Maq.assist. de tração n. ${ }^{\circ} 226$ & $\operatorname{Cz} \$ 44.348,81$ & Dissídio retroativo \\
\hline $12-02-1990$ & Maquinista fiscal de tração n. ${ }^{0} 78$ & $\operatorname{Cr} \$ 25.367,18$ & Equiparação salarial \\
\hline
\end{tabular}

Verifica-se tanto a variação do valor do salário, derivada na maioria no período de grande inflação que o Brasil passou nas décadas de 1980 e 1990, os reajustes do dia do trabalho ( $1^{\circ}$ de maio), assim como pela mudança nos cargos, subindo de auxiliar de maquinista no início para depois maquinista em vários níveis, até chegar a fiscal de maquinista de tração. Isto sem contar o período em que ele estava na presidência da Cooperativa dos Ferroviários da Regional Curitiba, onde exerceu inúmeras atividades administrativas, como a 
gerência de um mercado para o acesso dos ferroviários aos produtos com preço de custo, nos anos de 1990-1992. Percebe-se, portanto, uma grande sintonia com a profissão, onde a dedicação e a ascensão nos cargos podem ser interpretadas como o interesse nos assuntos tanto do trabalho como no social, atividades recreativas eram promovidas pelo grupo que participava.

Com relação à parte mais social da experiência ferroviária dos documentos selecionados, percebem-se claramente festas de aniversários, jogos de futebol, partidas de bocha, onde colegas de um setor disputavam partidas com os demais. Uma fita VHS possuí grande parte do seu conteúdo reservado na atividade de Olimpiadas dos Ferroviários de 1987. É a questão da sociabilidade envolvida nos assuntos do trabalho e do lazer, além de ser um dos elementos que constituíam o ferroviário, ou pelo menos a presença nestes eventos. Um motivo e um babitus de inclusão social. Havia premiações como troféus, e percebe-se que não era propriamente uma disputa, mas uma forma de lazer que unia experiências e grupos de funcionários. Geralmente estes jogos eram promovidos e organizados pelos próprios ferroviários, mostrando o interesse de se reunirem e terem uma prática social em comum. Eram situações de finais de semana, com churrascos, confraternizações, que acabavam envolvendo as famílias dos profissionais, extrapolando, portanto, os limites do saber-fazer dos ferroviários e seus horários de trabalho. Uma fotografia informa no seu verso a indicação da chegada da Maria-fumaça num Natal, onde os filhos dos funcionários esperavam ansiosos na Estação Rodo-ferroviária de Curitiba os presentes que seus pais podiam comprar, e que eram entregues pelo Papai Noel numa cerimônia de confraternização.

Fotografias feitas em serviço também são utilizadas nesta seleção. São cenas que ilustram os ferroviários em serviço, seja operando as locomotivas à vapor ou à óleo diesel, seja de funcionários consertando e fazendo a manutenção de trechos nos mais diversos ambientes. Um clima de amizade pode ser percebido, pois todos se identificam como colegas; algumas fotografias possuem nomes no verso, além de informações sobre a quantidade de vagões transportados e 0 local e data. As identificações pessoais com o ofício acabam sendo um motivo de orgulho, pois posar em frente a uma grande máquina denotava um espírito de satisfação, uma certa dominação e controle. Familiares também partilhavam deste processo, em viagens de turismo ou acompanhando os pais nas jornadas, o que acabava sendo uma grande aventura para aqueles. 
Figura 01

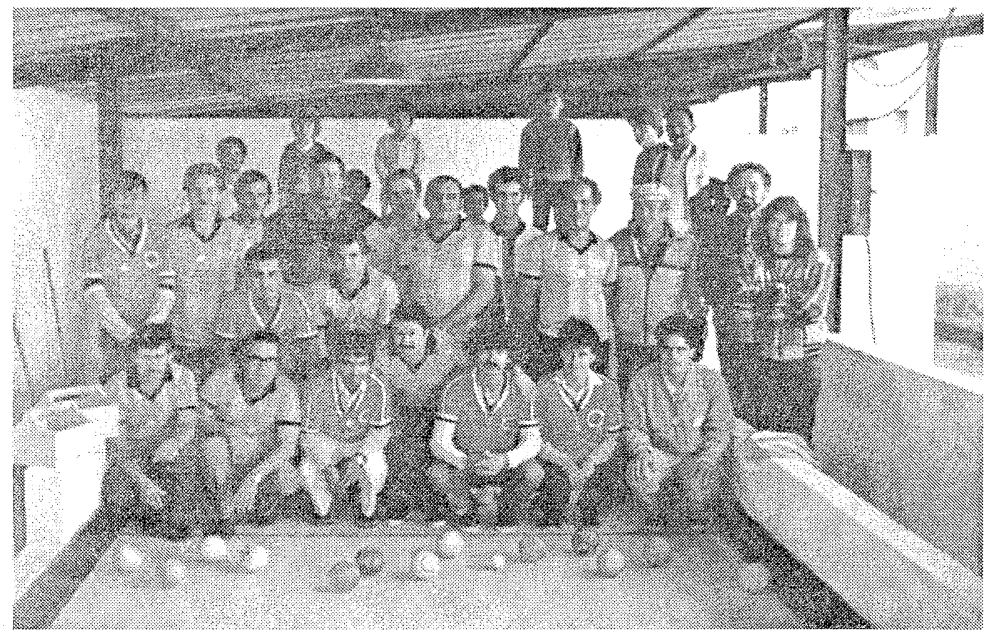

Representa uma reunião para jogos, festas e confraternizações.

Figura 02

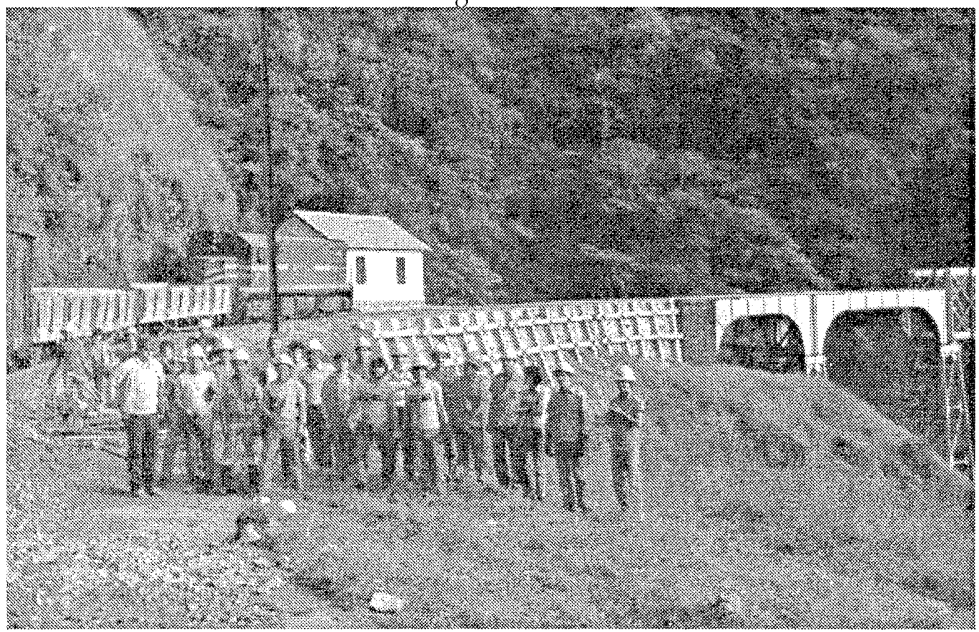

Grupo de operários em serviço, na ponte São João do trecho Paranaguá-

Curitiba. 
E por fim gostaria de citar alguns trechos de duas reuniões registradas em fitas. Uma aconteceu no dia 11 de junho de 1976, quando da convocação de funcionários interessados em elaborar uma constituição que pudesse ser reconhecida legalmente como a associação dos ferroviários (AFER):

[Ernesto Tiradentes] ... a intenção do grupo de, realmente, nós chegarmos a uma conclusão satisfatória daquilo que pretendemos. Estamos reunidos para conseguir ... comissão para por em prática o objetivo do grupo. Oferecer aos servidores da administraçãa regional Curitiba, através de uma associação, entretenimento no campo social, recreativo, cívico ecultural. Os elementos representados na delegação departamental, é o grupo idealizador da iniciativa. Consequentemente, os sócios fundadores que hoje iram consolidar o pensamento comum do grupo, criando condições administrativas, para iniciar já em termos de organização a nobre caminha rumo ao seu ideal. Vamos, sem fugir do objetivo, com calma eserenidade, desenvolver as proposições com o máximo de praticidade, peço a colaboraçã̃o de todose desde já agradeço. Vamos iniciar, eu proponho, fazendo a apresentação dos grupos. Então eu pediria para que o primeiro grupo da diretoria, para que todos fiquem conhecendo, eque se pronunciasse da maneira como vou me pronunciar. Ernesto Tiradentes de Sousa, chefe de seção... (Transcrito de fita K-7)

Ilustra exatamente este ideal de agrupar os funcionários para as relações culturais e sociais que foram descritas pelas fotografias de times de futebol, festas de final de ano, e pela própria cooperativa que depois acabou tendo o objetivo de ajudar com o mercado e seus departamentos sociais. A associação dos ferroviários tinha, portanto, a proposta de organizar eventos sociais que pudessem integrar os colegas de profissão, assim como um espaço onde questões trabalhistas poderiam ser tratadas com maior facilidade e rapidez, pelo contato com os departamentos da RFFSA.

E o outro trecho de fita refere-se a primeira reunião do Clube da MariaFumaça, uma organização que tinha objetivos de troca de experiências entre amantes da ferrovia. Um trecho da reunião foi gravado, e transcrevo a fala inicial do seu idealizador:

[Professor Machado] Nós pretendemos fazer algumas considerações rápidas, para a criação do Clube da Maria-Fumaça. As pessoas que compõem a mesa aqui são 
saudosistas, embora alguns não tenham os mesmos cabelos brancos que eu, mas são saudosistas da Maria-Fumaça. São os que sentem falta do apito da MariaFumaça, são aqueles que conhecem o que representa a nostalgia e a mensagem do apito da Maria-Fumaça. São aqueles que quando criança conviveram à beira da linha do trem, queriam todo dia buscar o jornal, o pacote que o trem trazia, que servia de comunicação da cidade grande e da cidade pequena. 0 lugar onde cada vez o trem parou para tomar água e lenha saiu uma cidade, e que nós infelizmente esquecemos disto. Então nós queremos reavivar, nós queremos recuperar essa memória que está sendo jogada fora ... Através da criação do nosso Clube da Maria-Fumaça, onde nós pretendemos defender, preservar essa memória que é muito cara para todos nós, especialmente estes que são ferroviários. E nós que temos a pretensão de dizer que não sendo ferroviário, nós também consideramos como tal, porque nós amamos a ferrovia. (Transcrito de fita VHS)

Mostram o interesse dos envolvidos na memória e nos hábitos que cercavam os ferroviários e seus amantes. É um aspecto muito interessante de ser explorado, principalmente porque se conecta com as experiências dos demais funcionários, em festas, jogos e apresentações do coral. 0 clube teria, portanto, a intenção de resgatar as experiências passadas que os tempos modernos estavam apagando, as lembranças das famílias e da infância, onde a vida destas pessoas não que eram apenas resumidas na ferrovia, mas possuíam uma cultura ferroviária, uma sociabilidade que envolvia as locomotivas e seus maquinistas.

\section{Algumas problemáticas e abordagens possíveis}

De parte dos documentos selecionados e descritos acima, algumas problemáticas podem ser elaboradas, conforme o enfoque e a escolha pela condução da escrita da narrativa histórica. Pode-se optar por uma base cronológica, iniciando pela reunião da formação da AFER em 1976, passando pelo ingresso de um ferroviário na RFFSA em 1981, as confraternizações e jogos promovidos e realizados pela AFER, principalmente na década de 1980, as cenas dos maquinistas e o pessoal da manutenção em serviço, finalizando com a fundação do Clube da Maria-Fumaça em 1987, cuja proposta era resgatar as experiências no ambiente ferroviário de seus membros. Esta opção 
seria um pouco mais descritiva, mas contaria certamente com elementos interpretativos como as relações nas ocasiões de jogos e o que poderia ser discutido nas reuniões da AFER. Não seria uma narrativa cronológica, mas teria apenas como condução a datação. Os temas estão obviamente inscritos na forma temporal.

Uma outra possibilidade de explorar os documentos seria pelo viés da memória, partindo da análise da fundação do Clube da Maria-Fumaça e todo o empenho e esforço de seus membros em resgatar experiências, como o próprio autor da maioria dos documentos selecionados neste trabalho. Tirar fotografias, fazer filmagens de jogos e festas, registrar o serviço dos funcionários é um ato de tentar preservar a memória, identificar-se e ter orgulho não apenas da profissão escolhida, mas da cultura e sociabilidade intrínseca neste processo. Fica explícito na própria prática de arquivar estes documentos.

E outra problemática poderia estar voltada mais para elementos do trabalho, como as alterações de salário, porque estão relacionadas principalmente por três fatores: a) a inflação do período; b) a mudança de cargos; c) e ocorriam sempre no dia do trabalho ( $1^{\circ}$ de maio) de cada ano, além de reajustes. Seria explorar esta questão do dia do trabalho e sua imagética inserida no mundo do trabalho, a ascensão na empresa.

Enfim, essas são apenas algumas propostas dentre inúmeras. Basta apenas que o aluno busque uma problemática e procure nos documentos elementos possíveis de relacionar suas perguntas, dando uma coerência no seu entendimento e na construção do conhecimento expresso na narrativa histórica.

\section{Um apoio conceitual e historiográfico aos documentos}

Trabalhar com documentos em estado de arquivo familiar - por mais que se refiram ao ambiente e às relações familiares - não é propriamente pesquisar a História da Família, principalmente quando os textos discutidos no início do trabalho aconselham a relação do conhecimento próximo do aluno com a realidade da sociedade mais ampla. Isto significa que por mais que os documentos sejam úteis na análise de um grupo de pessoas, como foi o caso dos documentos sobre os ferroviários, há a necessidade de além de pesquisar e analisar este grupo social, conectá-los com os contextos regionais. 
Sobre questões mais amplas, relacionadas ao Brasil na área econômica. e nas taxas de urbanização, os trechos de Bóris Fausto são bem explicativos e contextuais:

A 28 de fevereiro de 1986, Sarney anunciou ao país o Plano Cruzado através de uma rede nacional de rádio e televisão. 0 cruzeiro seria substituído por uma nova moeda forte - o cruzado - - na proporção de 1000 por 1; a indexação foi abolida; os preços e a taxa de câmbio foram congelados por prazo indeterminado e os aluguéis, por um ano. Houve preocupação em não se agravar a até em melhorar a situação dos trabalhadores. Reajustou-se o salário mínimo pelo valor médio dos últimos seis meses, mais um abono de $8 \%$. Os reajustes posteriores seriam automáticos sempre que a inflação chegasse a 20\%. (FAUSTO, 2003, p.522).

0 aluno articularia a inflação como alta contínua e generalizada dos preços, e os sindicatos pressionando para que houvesse constantes reajustes de salários. Isso estaria presente nas carteiras de trabalho selecionadas. Outros contextos podem ser explorados, como questões de urbanização e industrialização.

No início do século XX, a Revolução Industrial já havia se disseminado largamente. Do núcleo constituído inicialmente apenas pela Grã-Bretanha, a industrialização abarcou toda Europa Ocidental e Estados Unidos. Esse processo foi largamente impulsionado, até onde se pode perceber, pela própria Grã-Bretanha. Já a partir do início do século XIX, aquele país se transformou num grande exportador de máquinas a vapor, carvão e material ferroviário. Mais ainda, a partir dos excedentes acumulados, Londres tornou-se o centro mais importante do nascente capitalismo financeiro. Assim, aquele país estava plenamente capacitado a produzir e financiar a exportação dos bens de produção que tornavam a Revolução Industrial possível para toda uma gama de países na Europa e América. (OLIVEIRA, 2000, p.21)

Com o declínio da lucratividade da cafeicultura, a alternativa que pareceu mais atraente a uma maioria de grandes proprietários rurais foi a adoção da cultura da soja. Logo no primeiro governo da ditadura militar (1964-1985), o poder público federal começou a perseguir uma política de incremento das exportações. [...] Os efeitos da 
cultura de soja sobre a urbanização e a industrialização paranaenses foram enormes. A intensiva mecanização do cultivo e colheita do produto levou à dispensa de um número enorme de trabalhadores rurais. (OLIVEIRA, 2000, p.36)

Tomando a definição bastante restritiva de só considerar cidades as aglomerações com 20 mil ou mais habitantes, constatamos que em 1980 a maioria da população $(51,5 \%)$ passaram a ser urbanas, em contraste com os $16 \%$ de habitantes que viviam em cidades, em 1940. (FAUSTO, 2003, p. 532).

As políticas industriais do Paraná Contemporâneo deslanchadas a partir dos anos 60 perseguiram, da forma que thes pareceu ser a mais consistente, em cada conjuntura histórica específica, a industrialização do Paraná. Ao assegurar o financiamento direto ao produtor para expansão e criação de plantas industriais de vários ramos de atividade e bancando os investimentos na infra-estrutura produtiva (na versão Codepar), buscouse tornar o Paraná auto-suficiente no que diz respeito à produção industrial, procurandose romper com aquilo que se acreditava ser uma situação de dependência com relação a São Paulo. (OLIVEIRA, 2000, p.96).

São informações muito úteis a construção do entendimento do que foi o Paraná nas décadas de 1960-1990, mostrando a importância da soja como atividade econômica ao Estado, o processo intensificado de urbanização e industrialização, que provocou mudanças nas estruturas sociais e urbanísticas das principais cidades. Tudo isso pode ser articulado com a atividade ferroviária, que os produtos podem ser transportados em grandes quantidades pelos trens, não sobrecarregando e danificando as estradas de rodagem como os caminhões faziam e fazem, e também como estas transformações são caras à memória de seus frequentadores, como foi o caso de criar o Clube da Maria-Fumaça porque todas as lembranças estavam sendo apagadas pela modernidade.

0 aluno poderia fazer uma análise de comparação entre o período estudado e sua realidade; verificaria, por exemplo, naquela época qual a porcentagem de trabalhadores que possuíam carteira assinada, e hoje em dia, a diferença e como isso se reflete em questões sociais, econômicas e previdenciárias. E pesquisar igualmente as taxas de inflação naquele período e como elas estão atualmente. 
Estes trechos poderiam servir, em suma, como meios de estabelecer um diálogo dos documentos em estado de arquivo familiar com os conceitos; um apoio para a elaboração da narrativa histórica enquanto significadora do entendimento daquelas experiências expressas em forma de palavras, imagens ou sons.

\section{Conclusões parciais}

A reflexão sobre a realização deste trabalho pode ser dividida em duas partes. A primeira trata mais das considerações sobre os autores utilizados para pensar sobre o ensino de História e o uso de documentos em estado de arquivo familiar. Acredito que foram leituras impotantes para contextualizar e relacionar o conhecimento histórico conforme o período, ilustrando, pois, a construção do saber e sua utilização pedagógica como formadora da cidadania e consciência histórica. Com isso, ficou explícito que a abordagem de documentos guardados nas casas das pessoas possui uma finalidade, a saber: interagir a realidade do aluno com conceitos teóricos, propiciando uma empatia capaz de desenvolver o espírito crítico e a construção da narrativa história, ou ainda, a produção do saber.

Como este método acaba rompendo com o ensino de mera transmissão de conhecimento cronológico e até certo ponto teleológico, verificou-se nos documentos legais que a tematização é recurso didático possível de ser utilizado com estes documentos. Explora-se a sincronia (conteúdo) em detrimento da diacronia (linearidade), através de problematizações e questões sobre os documentos selecionados.

$\mathrm{Na}$ segunda parte da pesquisa, pude observar como manuseiar com estes conceitos. Optei então pela tematização dos conceitos de trabalho e cultura, pois notei que a problematização sobre as sociabilidades dos ferroviários estavam bem presentes nos documentos. Várias relações entre os documentos puderam ser sugeridas, enfatizando as idéias de experiência e cotidiano. Cheguei a conclusão de que o mundo do trabalho vai muito além das escalas e produtividade, sendo que memórias e festas estavam muito presentes, denotando, portanto, uma sintonia do grupo com a sua profissão. Ou ainda, pode-se observar como o grupo se reconhecia, qual a representação e eles procuravam transmitir e rememorar.

0 que fica de observação da pesquisa então realizada é que existe um 
enorme potencial de construção de conhecimento histórico no interior das residências, seja dos alunos, dos professores, ou de qualquer pessoa. Como foi dito no trabalho, a História pesquisa a ação dos homens no tempo, de qualquer grupo, independentemente se estão em livros ou não. A construção da narrativa histórica permite, em suma, recuperar as experiências dos grupos que compõem a sociadade, inserir no plano do ensino a dimensão da consciência que foi e é tão cara no mundo de ontem e de hoje. A satisfação de pesquisar os documentos guardados em casa, problematizá-los e refletir sobre o fazer historiográfico acaba sendo um incentivo a prática em sala de aula, ou seja, passar um entusiamos onde os alunos também possam fazer suas pesquisas, conhecerem mais sobre si e sobre os outros.

\section{Referências}

ARTIÈRES, Phillipe. Arquivar a própria vida. In: Estudos Históricos. Arquivos pessoais. Rio de Janeiro: Fundação Getúlio Vargas, 1998. vol. 11, n. 21.

BRASIL. Ministério da Educação. Parâmetros Curriculares Nacionais - Ensino Médio (PCNEM). Brasília: MEC/SEF, 1998.

CERRI, Luís Fernando. A função da História: orientação temporal e o ensino da História. Texto elaborado a partir do II Seminário Estadual para elaboração de diretrizes curriculares para o Ensino Fundamental - História. Faxinal do Céu, 2004a.

Luís Fernando. o que a História fez com a lógica de organização dos conteúdos, e o que o ensino de História fará com essa História? Texto elaborado a partir do II Seminário Estadual para elaboração de diretrizes curriculares para o Ensino Fundamental - História. Faxinal do Céu, 2004b.

FAUSTO, Bóris. História do Brasil. São Paulo: Edusp, 2003.

FURET, François. A oficina da História. Lisboa: Gradiva, [s.d.].

GARRIDO, Joan del Acàzar i. As fontes orais na pesquisa histórica: uma contribuição ao debate. In:Memória, história, historiografia. Dossiê ensino de História. Revista Brasileira de História. São Paulo: ANPUH / Marco Zero. vol. 13 n. 25/26, setembro 92 / agosto 93.

NADAI, Elza. 0 ensino de história no Brasil: trajetória e perspectivas. In: Memória, bistória, historiografia. Dossiê ensino de História. Revista Brasileira de História. São Paulo: ANPUH / Marco Zero. vol. 13 n. 25/26, setembro 92 / agosto 93. 
OLIVEIRA, Dennison de. Urbanização e Industrialização no Paraná. Curitiba: UFPR / SEED, 2000.

PARANÁ. Orientuções Curriculares de História. Texto Preliminar. Secretaria de Educação do Estado do Paraná. Departamento de Ensino Médio, 2005.

SCHMIDT, Maria Auxiliadora \& CAINELLI, Marlene. Ensinar História. São Paulo: Scipione, 2004.

SCINIDT, Maria Auxiliadora \& GARCIA, Tânia Maria. Perspectivas da formação da consciência histórica e da consciência crítica em aulas de História. Conferência proferida na X Semana Paulo Freire. Fortaleza: Museu do Ceará, 2005.

\section{At the railroad culture tracks: documents from family archives in History teaching.}

ABSTRACT

This article deals with the historicity of History teaching, pointing how the methodology of History was used and which has been its purposes. After that, this research defines some of the characteristics of History teaching, and one of nowadays purposes, using jointly the subject themes and the family font archives. Later on, this article describes a possible example of family font archives, present in the author's own family ones, corcerning the profession connected to the railroad and the cultural and social issues involved in this work. It brings up questions, at the same time that a historiography support is used to link the family documents with the theme concepts of culture, memory and work.

Key-words: History teaching, Building of History knowledge, Family documents. 